\title{
The Boston keratoprosthesis 2014: a step in the evolution of artificial corneas
}

\author{
Claes H. Dohlman · Andrea Cruzat · Michelle White
}

Received: 20 November 2014 / Accepted: 26 November 2014 / Published online: 28 January 2015

(C) The Author(s) 2014. This article is published with open access at Springerlink.com

\begin{abstract}
Summary "Artificial corneas" have been attempted in severe corneal disease for at least 230 years, with largely disappointing results until recently. 'The Boston Keratoprosthesis' (B-Kpro) has been part of this history on and off for a half century. Developed from several previously known concepts, it was originally made of PMMA plastics in a collar button design (Type I), to be implanted into a corneal graft carrier and then transplanted to the patients' cornea. (A Type II with an additional stem for lid penetration is occasionally used in end-stage dry eyes.)

Management and device changes have over the years led to marked clinical improvements. Thus, postoperative infections have been drastically reduced by using low-dose prophylactic antibiotics. The corneal surface has been found to be well protected from evaporative damage by a soft contact lens or a conjunctional flap. Postoperative tissue melt around the device has been markedly reduced by improvement of nutrition from the aqueous (perforated back plates) and better anti-inflammatory strategies. Titanium alloys can be used for nontransparent parts to reduce inflammation and increase biointegration. Retroprosthesis membranes and retina
\end{abstract}

In April 2014, the 9th International Conference on Keratoprostheses was held in Salzburg, Austria, under the chairmanship of Professor Günther Grabner. At his request, contributions from Boston will be summarized here, with appropriate historical background. Participants from Boston were Drs James Chodosh, Joseph Ciolino, Kathryn Colby, Alja Črnej, Andrea Cruzat, Claes Dohlman, Larisa Gelfand, Christina Grassi, Eleftherios Paschalis, Marie-Claude Robert, Borja Salvador, Elise Taniguchi, and Michelle White.

C. H. Dohlman, MD, PhD $(\varangle) \cdot$ A. Cruzat · M. White

Boston Keratoprosthesis Research and Development,

Massachusetts Eye and Ear Infirmary,

243 Charles Street,

02114 Boston, MA, USA

e-mail: claes_dohlman@meei.harvard.edu complications have similarly been markedly reduced. However, post-operative glaucoma is still a stubborn problem that can cause long-term attrition of vision. Autoimmune diseases are particularly treacherous and B-KPros should not at present be used routinely. About 12,000 Boston Keratoprostheses have so far been distributed world-wide. Robust research is presently on-going to improve long-term safety, especially for the developing world.

Keywords Artificial cornea $\cdot$ Keratoprosthesis

\section{Die Boston-Keratoprothese 2014 - Ein Schritt in der Entwicklung künstlicher Hornhäute}

Zusammenfassung „Künstliche Hornhäute“ stehen seit zumindest 230 Jahren in der Behandlung schwerer Hornhauterkrankungen mit bis zuletzt meist enttäuschenden Ergebnissen im Einsatz. Seit einem halben Jahrhundert ist die ,Boston-Keratoprothese' (B-KPro) immer wieder Teil dieser Entwicklungen gewesen. Die B-KPro wurde aus verschiedenen bekannten Konzepten heraus entwickelt und bestand ursprünglich aus PMMA-Plastiken im Kragenknopf-Typ (Typ I), die in den Transplantatträger implantiert und schließlich in die Hornhaut der Patienten transplantiert wurden. (Ein Typ II mit einem zusätzlichen Stiel zur Lidpenetration wird gelegentlich bei starkem Sicca-Syndrom verwendet.)

Therapeutische und apparative Veränderungen haben in den letzten Jahren zu deutlichen klinischen Verbesserungen geführt. So wurden postoperative Infektionen durch den Einsatz von niedrigdosierten prophylaktischen Antibiotika tiefgreifend verringert. Weiche Kontaktlinsen oder Bindehautflaps dienen heute dem Schutz der Hornhautoberfläche vor evaporativen Schädigungen. Postoperative Gewebseinschmelzungen um das Instrument wurden durch eine verbesserte Versorgung 
aus dem Kammerwasser und gezieltere anti-inflammatorische Strategien deutlich reduziert. Titanlegierungen können bei nicht-transparenten Bestandteilen zur Eindämmung von Entzündungen und Erhöhung der Biointegration eingesetzt werden. Ein hartnäckiges Problem ist allerdings nach wie vor das postoperative Glaukom, das eine langzeitliche Abnahme der Sehkraft bewirken kann. Darüber hinaus sind Autoimmunerkrankungen besonders heimtückisch, sodass B-KPros noch nicht in der Routinebehandlung verwendet werden sollten. An die 12.000 B-KPros sind bisher weltweit im Umlauf. Intensive Forschungen widmen sich der Verbesserung der längerfristigen Sicherheit, insbesondere in Entwicklungsländern.

Schlüsselwörter Künstliche Hornhaut · Keratoprothese

\section{Introduction}

Attempting to restore vision in an eye with severe corneal opacities by implanting a window of transparent foreign material into the cornea is an obvious concept which has attracted skilled surgeons and sharp minds for more than 2 centuries (for history, see Cardona [19] Dohlman [29] Mannis and Dohlman [54]). The problem, however, has been in its execution. Complications (infections, glaucoma, retinal detachments, etc.) have traditionally been frequent and severe, often leading to loss of the eye. Not until the mid-1900s did prospects improve somewhat with the introduction of antibiotics and corticosteroids. Also, identification by several investigators of transparent and relatively inert plastics (polymethylmethacrylate, etc.) for the manufacturing of devices (particularly Stone and Herbert [78]), as well as the introduction of better surgical techniques at that time, resulted in improved keratoprosthesis (KPro) outcomes. Moreover, varied KPro designs were presented by a number of investigators in the early 1950s-virtually all presently used configurations were already suggested at that time (reviewed by Cardona [19]).

In spite of these developments, skepsis against the routine use of KPros was still widespread for decadesunderstandably, due to the still high rate of complications. In Boston, our first efforts in this difficult field were made in the mid-1960s (Dohlman et al. [32]) but it was not until 1989 that we gave the subject top priority. Food and Drug Administration granted marketing clearance for our Boston Keratoprosthesis (B-KPro) in 1992. Since then, faculty members, plus generations of fellows at the Massachusetts Eye and Ear Infirmary (MEEI)/Harvard Medical School have continued to try to create somewhat of a scientific basis for future refinements. Some metrics: 36 B-KPros were implanted 1965-1973 (C.H.D.), about 420 during 1990-2010 (C.H.D.), and another about 500 were implanted by other MEEI colleagues 2000-present. Among the above-mentioned 420 cases $80 \%$ were of Type I and the rest Type II (see below). Worldwide about $11,000 \mathrm{~B}-K$ Pros have now been used in over 50 countries.
Close to 300 publications from several groups have been published on the subject (Boston Keratoprosthesis Bibliography, 2013, 2014). The steps in the development of the B-KPro will now be summarized here.

\section{Design and materials}

After trials with radically different KPro designs, we settled on a collar button-shaped polymethylmethacrylate (PMMA) device, to be implanted into a carrier corneal graft-this combination then transplanted and sutured into the patient's cornea like a standard graft [31] (Fig. 1). It was felt that retention was improved by placing the haptic (the back plate) totally behind the cornea, rather than having it placed in the stroma. Later, large holes in the back plate were made to facilitate diffusion of nutrients from the aqueous to the graft keratocytes [42]. Also a new threadless design was introduced to better protect the graft Descemet's membrane and endothelium of the graft from damage during assembly [34]. The metal titanium, which has been widely used elsewhere in the body, and had previously been incorporated as intrastromal haptics in KPro devices [45, 51, 55], was adopted by us as back plate in 2005 (Fig. 2). We have found this material (actually an alloy, medical grade 23, consisting of titanium $90 \%$, aluminium $6 \%$, and vanadium $4 \%$ ) to be better tolerated by corneal tissues than PMMA, in vitro as well as in vivo $[4,79]$. The somewhat shiny appearance of the metal can be cosmetically troublesome (Fig. 2) but it can be dampened by electrolysis, creating a blue or brown surface [61] (Tinted soft contact lenses can also be cosmetically helpful). The diameter of the titanium back plate is normally chosen as 8.5 , or $7.0 \mathrm{~mm}$, but in selected cases, a larger diameter $(9.5 \mathrm{~mm})$ has been found to clamp the graft wound better and may reduce the incidence of retroprosthesis membranes (RPMs), anterior synechia formation, and possibly even glaucoma [25], although the subject is still controversial. Recent experiments have shown that coating also the stem of the B-KPro with titanium strongly improves tissue adhesion, most likely making passage of bacteria or fungi into the eye less likely [72]. Coating the stem with a thin, inert antimicrobial substance may have similar effect [11].

Another design, labeled B-KPro II (Fig. 1) has an added anterior nub to protrude between closed lids or through the upper lid-similar to lid arrangement used by Strampelli (1963) and DeVoe [19]. This device is reserved for the most desperate of corneal diseases such as totally dry eyes from autoimmune diseases or chemical burns $[16,59,75]$.

\section{Carrier tissue}

The Boston KPro requires a carrier corneal graft-without which surgery becomes forbiddingly complex [31]. In some cases, the patient's own cornea (autograft) can be used, trephined out, and assembled with the B-KPro on 
Fig. 1 a Assembly of Boston keratoprosthesis (B-KPro) Type I. In another modification the locking ring is eliminated and the back plate snaps directly onto the stem. $\mathbf{b}$ B-KPro Type I with polymethylmethacrylate (PMMA) back plate. c B-KPro Type I and II. d B-KPro Type II through the upper lid in Stevens-Johnson syndrome

Fig. 2 Boston keratoprosthesis Type I with titanium back plate
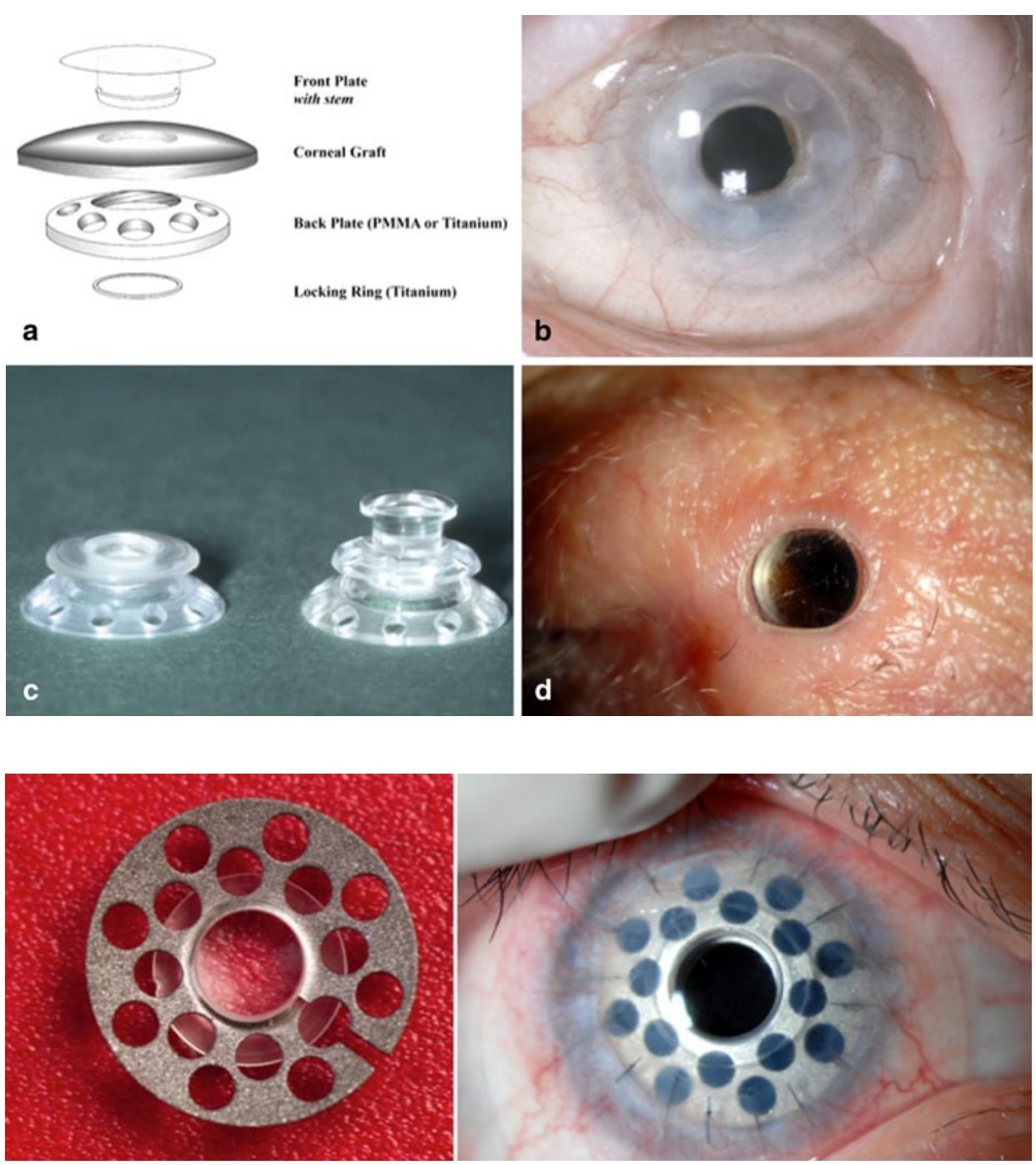

a side table before being sutured back into the patient's eye [5]. Most often, however, Eye Bank allografts are used which incur heavy cost due to the necessary testing and administration. Allogenous corneas have been modified to reduce antigenicity or improve storage and shipment. Thus, it has been shown that frozen (thus decellularized) corneas are well tolerated as B-KPro carriers [67]. Likewise, several centers have used $\gamma$-radiated corneas with success, again facilitating storage and shipment [2, 39]. In order to reduce postoperative tissue melt, carrier corneas have also been cross-linked with ultraviolet (UV) light which has been shown to convey considerable resistance to enzymatic digestion in vitro [8]. Clinically such corneas have been employed as carriers with success $[47$, 69]. For the developing world, however, less expensive alternatives must be sought when autografts are not possible; experiments with $\gamma$-radiated porcine xenografts, supplemented with a total conjunctival flap, and other possibilities are presently ongoing [26].

\section{Prognostic categories}

Rapidly, it became clear to us that the prognosis for a successful B-KPro outcome varied markedly between preoperative disease categories. This observation had been made previously to a degree in various settings [37]. Still, we scrutinized numerically the outcome in various preoperative eye or systemic disease categories, with quite revealing results [82]; the small but important group of presumed autoimmune diseases (Stevens-Johnson syndrome, mucous membrane pemphigoid, graft-vs-host disease, atopy, uveitis, etc.) had by far the worst outcome, with chemical burns more favorable (Fig. 3). In the large group of non-autoimmune corneal diseases, such as dystrophies, post-infections graft failures, etc., the B-KPro did rather well. The common adverse denominator was clearly the degree of preoperative chronic inflammation. Subsequent outcome studies for subgroups followed for: Herpes simplex keratitis [48], Herpes zoster [63], aniridia [1], epithelial downgrowth into the anterior chamber [73], etc.- -all showed quite good retention [22]. It is clearly in this general category of relatively low degree of inflammation that the B-KPro does the most good, with 
Fig. 3 Acid burn pre- and postoperatively. Boston Keratoprosthesis Type I since 15 years. Vision 20/40
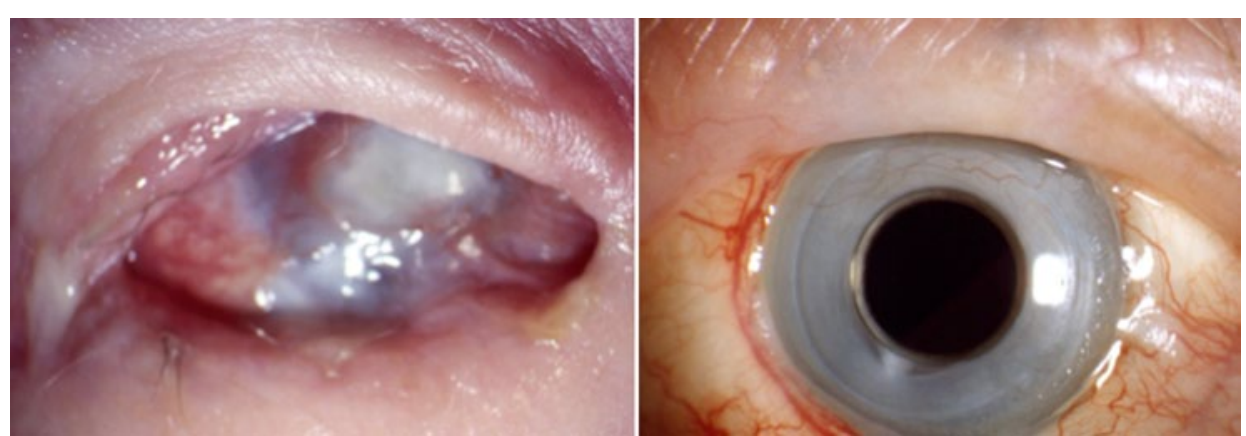

the possible exception of pediatric KPro which remains challenging [7]. These outcomes have been well documented also from other institutions in numerous studies (Boston Keratoprosthesis Bibliography, 2013, []). After one standard corneal graft failure, it is often the safest to implant a B-KPro instead of doing a repeat graft [52]. Also in some cases of severe corneal blindness with poor prognosis for keratoplasty, there is justification in using a B-KPro as a primary procedure instead of starting with a standard graft [20].

As mentioned, the autoimmune disease category turned out to be the most difficult subgroup (see below). This has led us to conclude that B-KPros presently should not be implanted routinely in autoimmune diseases and that work on this category should for the moment be restricted to carefully structured studies in academic settings. Research to improve outcome in this group is presently intense.

The various categories of complications will now be summarized here.

\section{Infections, prophylaxis}

Endophthalmitis, usually from gram-positive bacteria, frequently results in total vision loss and it is one of the most feared complications after a KPro. However, since 1990 we have gradually shown that surprisingly low doses of daily antibiotics have a very strong prophylactic effect $[12,27,57]$. Over the years we have come to prefer the combination of Polymyxin B and trimethoprim (Polytrim $^{\mathrm{TM}}$ drops, effective against both gram-positive and most gram-negative bacteria), and titration has shown that one drop a day gives sufficient coverage in nonautoimmune cases [12]. In the most critical situations (autoimmune, only eyes, etc.), we add vancomycin $(1.4 \%)$ once or twice daily [38]. Compliance with the daily regimen is of course important and cannot be taken for granted. Therefore, the recent development of a soft contact lens that can elute antibiotics at an even rate (zero order release) for a month, promises to be quite useful in the future [21]. Looking back, the introduction of a daily low-dose antibiotics prophylaxis for life has been the most important step toward long-term safety of penetrating artificial corneas.

In large parts of the world, especially where the climate is hot and humid and where agricultural work is predominant, fungal keratitis is common. In a B-KPro eye, fungal colonization is easily missed clinically and a prophylactic regimen against the common fungi would be desirable. The search for an inexpensive practical and effective such regimen is presently underway.

\section{Necrosis, tissue melt}

Necrosis and melt of the tissue around the KPro can lead to aqueous leak, infection, or extrusion, and this complication is more prevalent in patients with autoimmune diseases [82]. In these patients the level of matrix metalloproteinases in tears is elevated [9]. Fortunately, the incidence of tissue melt became markedly reduced with the introduction of the aforementioned perforated back plate, improving tissue nutrition for the carrier graft [42]. Anti-collagenase medication such as $1.0 \%$ suspension of medroxyprogesterone $[29,44,49]$ two to three times daily, and topical $(0.1 \%)$ or systemic doxycycline are definitely helpful. Dramatic effects have been seen following systemic infusion of the tumor necrosis factor-alpha (TNF- $\alpha$ ) inhibitor infliximab in a small group of cases of B-KPro in rheumatoid arthritis and Stevens-Johnson syndrome [32, 35]. Topical infliximab is now being evaluated in similar situations [70]. Also as mentioned above, cross-linked carrier corneas may prevent postoperative melt.

\section{Glaucoma}

After corneal complications such as melt and infection have gradually been brought under reasonable control, it is clear that glaucoma has emerged as the greatest obstacle to long-term success of the KPro [56]. Most patients being evaluated for KPro, in our studies as well as in others, have had glaucoma prior to B-KPro surgery [68]. Subsequently, the glaucoma often worsens, as has been measured by changes in cup/disc ratio and visual fields [24]. In a recent example from the field, $90 \%$ of the patients in a Thai study experienced prompt improvement of vision with B-KPro surgery, compared with preoperatively, but this percentage decreased to $55 \%$ after 6 years. The primary reason for the visual decline was glaucoma-no glaucoma drainage device had been implanted before or simultaneously with the B-KPro [50]. We feel that an early glaucoma drainage device, specifi- 
cally a valved shunt (Ahmed), is very helpful in retarding further deterioration and should be routinely employed in all cases of B-KPro surgery when glaucoma has been documented preoperatively. Still, dangerous pressure rises can occur later over the years and new shunt principles need to be introduced to fit the B-KPro situation. One device, based on ferromagnetic principles and responding to both opening pressure and closing pressure, presently is being developed and tested [60]. In the severest cicatrizing situations, aqueous may have to be shunted to lower lid fornix or to one of the sinuses, thus to atmospheric pressure outside the eye [36]. This principle is surprisingly safe against infection and it might also be applicable in extremely dry eyes where aqueous shunted to the lower lid fornix can serve as "tears" [30]. Also, cyclophotocoagulation in some form is often used after B-KPro [66].

Managing glaucoma in a B-KPro eye is particularly challenging since it is difficult to determine the intraocular pressure. Indentation tonometry is not reliable due to the back plate size and rigidity and therefore only gross estimation with finger palpation remains presently available. However, it has recently been shown that a small German-made ring-shaped pressure transducer (Implandata ${ }^{\mathrm{TM}}$ ), encapsulated in silicone rubber, can be implanted safely behind the iris, and the pressure be registered by radio waves with a recording device from the outside [78]. Promising clinical trials are currently under way [54].

The development of glaucoma after B-KPro surgeryactually after any corneal surgery-raises questions about the pathophysiology of the optic nerve damage. In many cases of B-KPro the intraocular pressure remains normal postoperatively but the optic nerve head can still gradually become cupped and pale. This sequence of events is particularly obvious after chemical burn, especially alkali burns [16]. Subsequent investigations showed absence of direct diffusion of alkali to the retina level and instead it seems that inflammatory cytokines are generated by the burn in the anterior segment and rapidly diffuse posteriorly to cause ganglion cell apoptosis and other cell damage. TNF- $\alpha$ is probably one such inflammatory mediator because intraperitoneal injection of its inhibitor infliximab soon after corneal burn in mice, strongly protects the ganglion cells from apoptosis [17]. This raises the future possibility of being able to protect chemical burn patients from posterior segment damage by promptly infusing infliximab or similar inhibitor while the patient receives ocular lavage in the emergency room. Later, in a less-inflamed stage, the cornea can be implanted with a B-KPro with high likelihood of success [16].

Intraocular inflammation, sterile vitritis, retinal detachment

Many patients with severe corneal damage may also have low-grade inflammation prior to KPro surgery but, in the presence of a cloudy cornea, such inflammation is difficult to diagnose preoperatively. Such a situation is likely to get worse with every subsequent surgical procedure, including a B-KPro. It can result in RPM, vitreous opacities, cystoid macular edema, epiretinal membrane, or-worst of all-a retinal detachment, which has a poor record of repair [40, 46, 65]. Again, autoimmune disease is the leading risk factor. A vision-reducing RPM used to be the most common complication after B-KPro [29]. In most cases, the membrane can be sufficiently opened by cautious yttrium aluminium garnet (YAG) laser [10] but when dense and vascularized, total reoperation with open-sky membranectomy seems to be the least traumatic. The incidence of RPM has been steadily falling and, as mentioned above, using a back plate of titanium rather than PMMA reduces the rate of membrane formation [79]. In addition, costicosteroids, TNF- $\alpha$ inhibitors, medroxyprogesterone, doxycycline, etc. can be helpful in bringing the often subtle inflammation under control. Ongoing laboratory experiments with a miniature Boston-type KPro, implanted into mice corneas and followed by quantitative analysis of inflammatory cytokines and cells, promise to clarify the mechanisms [23].

"Sterile vitritis" is a peculiar form of uveitis/endophthalmitis that is classically characterized by very sudden (often overnight), massive vitreous opacities, but which in most cases results in eventual clearing and restored vision $[41,58,64]$. It may be triggered by YAG laser treatment, eye rubbing, or other factors. Corticosteroids (topical, subtenon) expedite resolution. The incidence seems to be around $5-15 \%[40,41]$. The main problem with sterile vitritis is the difficulty of being certain early in the process that a bacterial endophthalmitis is not present.

\section{Ocular surface protection}

The introduction of around-the-clock wear of large soft contact lenses represented a major step toward B-KPro safety [33]. For instance, a $16 \mathrm{~mm}$ Kontur $^{\mathrm{TM}}$ lens is well tolerated and distributes evaporative forces well, protecting the surface. Some lenses cannot be retained [43] and a few patients develop central deposits from poor blinking [14], but the majority do well. If deposits occur, replacement with a hybrid lens with a hard center usually solves the problem. Tinted or painted lenses with a clear center are useful to reduce glare or to improve cosmetics [76].

Under circumstances when soft contact lens wear is not expected to be feasible due to cost or poor retention, a total conjunctival flap (if possible to mobilize) with a central opening can be a satisfactory substitute. A total, loose flap from the temporal side might be drawn over the fully de-epithelialized cornea and anchored at the limbus with fine nylon sutures [3]. The flap results in building up tissue peripheral to the anterior plate of the B-KPro, preventing tissue melt and contributing to good retention and safety even in the absence of a soft lens. Thus, a conjunctival flap works well but adds to surgery time. 


\section{Optics, glare}

The optical qualities of the B-KPro have been well documented and the data should be applicable to other suggested devices as well as [76]. It was once feared that prolonged B-KPro surgery combined with the near perfect optics of the device would allow light damage of the central retina during the procedure. However, UV filters in modern operating microscopes plus the UV-blocking quality of the PMMA, have been shown to practically eliminate the risk of macular damage [71]. The B-KPro stem allows wide-angle photography of the retina [74]. A major clinical problem can be heavy glare in the absence of iris or in the presence of a substantial RPM-any tissue that can scatter entering light can result in disturbing glare effect. An intraocular "artificial pupil" or a tinted contact lens can bring some amelioration.

\section{Epidemiology, future needs}

The future need for a well-functioning, long-term safe KPro is hard to project. It is obviously dependent on the number of people worldwide with bilateral corneal blindness. Such estimates are presently very soft but seem to indicate a number of 4-8 million [62], the vast majority of all blindness occurring in the developing world [81]. The unmet need for a KPro is furthermore dependent on the long-term outcome of standard corneal transplantation-taking into account that 5-year survival in developing countries is notoriously low. In addition, outcomes of regrafts are also usually way below those of primary grafts [13]. Also in the Western World, victims blind from autoimmune diseases or chemical burns have very poor outcome with standard corneal transplantation and they need another surgical option. The number of people bilaterally blind from chemical burns or Stevens-Johnson syndrome, per year, can now be calculated with some precision [80]. From all this, it is clear that a backup "rescue" procedure of some kind is needed although it is presently uncertain whether a KPro is the best option once a standard graft has failed. Under any circumstances, the world needs a reliable and safe KPro, but it must also be affordable. The cost-effectiveness ratio of the B-KPro Type I is not far off from that of standard keratoplasty [6] but this is not enough for the developing world. The inexpensive Lucia KPro model may fulfill the cost requirements for the device (Chodosh, personal communication) but the cost of the carrier graft and, often, a glaucoma shunt must be included in the calculations. Most likely, with improvements, the need for a KPro in the future will be very substantial, perhaps over 100,000 new cases per year.

\section{Conclusions}

Development of artificial corneas has come a long way in the last half century. For the Boston KPro we have been happy to see that the rate of postoperative endophthalmitis has decreased about 10-fold over 2 decades-due to prophylactic antibiotics. Corneal melt around the device has likewise decreased by about a log unit to about $3 \%$ over the first 17 postoperative months [22]. The retroprosthetic membrane is clearly diminishing in frequency and may be on its way out. However, while the Boston KPro of 2014 has made great improvements over the past 50 years, we still have a road to travel until we have a truly effective, inexpensive and, most importantly, a long-term safe procedure with low rate of postoperative inflammation, glaucoma, or retinal detachment even for the most severe cases, in resourcepoor countries.

\section{Conflict of interest}

All authors are full-time employees of Massachusetts Eye and Ear Infirmary (a not-for-profit organization) which is the manufacturer of the Boston Keratoprosthesis.

\section{Open Access}

This article is distributed under the terms of the Creative Commons Attribution License which permits any use, distribution, and reproduction in any medium, provided the original author(s) and the source are credited.

\section{References}

1. Akpek EK, Harissi-Dagher M, Petrarca R, Butrus SI, Pineda R II, Aquavella JV, Dohlman CH. Outcomes of Boston keratoprosthesis in aniridia: a retrospective multicenter study. Am J Ophthalmol. 2007;144:227-31.

2. Akpek EK, Aldave AJ, Aquavella JV. The use of precut, $\gamma$-irradiated corneal lenticules in Boston type I keratoprosthesis implantation. Am J Ophthalmol. 2012;154:495-8.

3. Al-Merjan J, Sadeq N, Dohlman CH. Temporary tissue coverage of keratoprosthesis. Middle East J Ophthalmol. 2000;8:12-8.

4. Ament JD, Spurr-Michaud SJ, Dohlman CH, Gipson IK. The Boston keratoprosthesis: comparing corneal epithelial cell compatibility with titanium and PMMA. Cornea. 2009;28:808-11.

5. Ament JD, Tilahun Y, Mudawi E, Pineda R. Role for ipsilateral autologous corneas as a carrier for the Boston keratoprosthesis: the Africa experience. Arch Ophthalmol. 2010a;128:795-7.

6. Ament JD, Todani A, Pineda R, Shen TT, Aldave AJ, Dohlman $\mathrm{CH}$, Chodosh J. Editorial: global corneal blindness and the Boston keratoprosthesis type I. Am J Ophthalmol. 2010b;149:537-9.

7. Aquavella JV, Gearinger MD, Akpek EK, McCormick GJ. Pediatric keratoprosthesis. Ophthalmology. 2007;114:989-94.

8. Arafat SN, Robert M-C, Shukla AN, Dohlman CH, Chodosh J, Ciolino JB. UV cross-linking of donor corneas confers resistance to keratolysis. Cornea. 2014a;33:955-9.

9. Arafat SN, Suelves AM, Spurr-Michaud S, Chodosh J, Foster CS, Dohlman CH, Gipson IK. Neutrophil collagenase, gelatinase, and myeloperoxidase in tears of patients with Stevens-Johnson syndrome and ocular cicatricial pemphigoid. Ophthalmology. 2014b;121:79-87. 
10. Bath PE, McCord RC, Cox KC. Nd: YAG laser discission of retroprosthetic membrane: a preliminary report. Cornea. 1983;2:225-8.

11. Behlau I, Mukherjee K, Todani A, Tisdale AS, Cade F, Wang L, Leonard EM, Zakka FR, Gilmore MS, Jakobiec FA, Dohlman $\mathrm{CH}$, Klibanov AM. Biocompatibility and biofilm inhibition of $\mathrm{N}, \mathrm{N}$-hexyl,methyl-polyethylenimine bonded to Boston keratoprosthesis materials. Biomaterials. 2011;32:8783-96.

12. Behlau I, Martin KV, Martin JN, Naumova EN, Cadorette JJ, Sforza JT, Pineda R II, Dohlman CH. Infectious endophthalmitis in Boston keratoprosthesis: incidence and prevention. Acta Ophthalmol. 2014;92:1-10.

13. Bersudsky V, Blum-Hareuveni T, Rehany U, Rumelt S. The profile of repeated corneal transplantation. Ophthalmology. 2001;108:461-9.

14. Beyer J, Todani A, Dohlman C. Prevention of visually debilitating deposits on soft contact lenses in keratoprosthesis patients. Cornea. 2011;30:1419-22.

15. Boston Keratoprosthesis Bibliography. Boston Keratoprosthesis Newsletter 2013 and 2014. http://www.masseyeandear.org/for-professionals/physician-resources/ keratoprosthesis/. Accessed: 1 Sept 2014.

16. Cade F, Grosskreutz CL, Tauber A, Dohlman CH. Glaucoma in eyes with severe chemical burn, before and after keratoprosthesis. Cornea. 2011;30:1322-7.

17. Cade F, Paschalis EI, Regatieri CV, Vavvas DG, Dana R, Dohlman $\mathrm{CH}$. Alkali burn to the eye: protection using TNF- $\alpha$ inhibition. Cornea. 2014;33:382-9.

18. Cardona H. Keratoprosthesis; acrylic optical cylinder with supporting intralamellar plate. Am J Ophthalmol. 1962;54:284-94.

19. Cardona H, DeVoe AG. Prosthokeratoplasty. Trans Am Acad Ophthalmol Otolaryngol. 1977;83:271-80.

20. Chang HP, Luo ZK, Chodosh J, Dohlman CH, Colby KA. Primary type I Boston keratoprosthesis in non-autoimmune corneal diseases. Submitted to Cornea; 2014.

21. Ciolino JB, Hoare TR, Iwata NG, Behlau I, Dohlman CH, Langer R, Kohane DS. A drug-eluting contact lens. Invest Ophthalmol Vis Sci. 2009;50:3346-52.

22. Cilolino JB, Belin MW, Todani A, Al-Arfaj K, Rudnisky CJ, Boston Keratoprosthesis Type 1 Study Group. Retention of the Boston keratoprosthesis type 1: multicenter study results. Ophthalmology. 2013;120:1195-200.

23. Crnej A, Omoto M, Dohlman TH, Graney JM, Dohlman CH, Drnovsek-Olup B, Dana R. A novel murine model for keratoprosthesis. Invest Ophthalmol Vis Sci. 2014a;55:3681-5.

24. Crnej A, Paschalis EI, Salvador-Culla B, Tauber A, Drnovsek-Olup B, Shen LQ, Dohlman CH. Glaucoma progression and role of glaucoma surgery in patients with Boston keratoprosthesis. Cornea. 2014b;33:349-54.

25. Cruzat A, Shukla A, Dohlman CH, Colby K. Wound anatomy after type 1 Boston KPro using oversized back plates. Cornea. 2013a;32:1531-6. doi:10.1097/ICO.0b013e3182a854ac.

26. Cruzat A, Tauber A, Shukla A, Paschalis EI, Pineda R, Dohlman $\mathrm{CH}$. Low-cost and readily available tissue carriers for the Boston keratoprosthesis: a review of possibilities. J Ophthalmol. 2013b;2013:686587.

27. Dohlman CH. Post operative regimen and repair of complications after keratoprosthesis surgery. Refract Corneal Surg. 1993;9:198.

28. Dohlman CH. Pellier de Quengsy and his keratoprosthesis. In: Mannis MJ, Mannis AA, editors. Corneal transplantation. Oostende: JP Wayenborgh; 1999. pp. 52-64.

29. Dohlman $\mathrm{CH}$, Doane MG. Some factors influencing outcome after keratoprosthesis surgery. Cornea. 1994;13:214-8.
30. Dohlman CH, Dohlman JG. Aqueous shunt to the ocular surface for severe dry eyes. Digit J Ophthalmol. 2005;11:2.

31. Dohlman $\mathrm{CH}$, Webster RG, Biswas SK, Doane MG, Holmberg A. Collar-button prosthesis glued to a corneal graft. In: Polack FM, editor. Corneal and external diseases of the eye. Charles C. Thomas, Springfield, Illinois; 1970. pp 189-92.

32. Dohlman $\mathrm{CH}$, Dudenhoefer EJ, Khan BF, Dohlman JG. Corneal blindness from end-stage Sjögren's syndrome and graft-versus-host disease. Adv Exp Med Biol. 2002a;506:1335-8.

33. Dohlman CH, Dudenhoefer EJ, Khan BF, Morneault S. Protection of the ocular surface after keratoprosthesis surgery: the role of soft contact lenses. CLAO J. 2002b;28:72-4.

34. Dohlman CH, Harissi-Dagher M, Graney J. The Boston keratoprosthesis: a new threadless design. Digit J Ophthalmol. 2007;13:1-2.

35. Dohlman JG, Foster CS, Dohlman CH. Boston keratoprosthesis in Steven-Johnson syndrome: a case of using infliximab to prevent tissue necrosis. Digit J Ophthalmol. 2009;15:1-2.

36. Dohlman CH, Grosskreutz CL, Chen TC, Pasquale LR, Rubin PAD, Kim EC, Durand M. Shunts to divert aqueous humor to distant epithelialized cavities after keratoprosthesis surgery. J Glaucoma. 2010;19:111-5.

37. Donn A. Additional follow-up of 34 cases of prosthokeratoplasty. Trans Am Acad Ophthalmol Otolaryngol. 1977;83:281.

38. Durand ML, Dohlman CH. Successful prevention of bacterial endophthalmitis in eyes with the Boston keratoprosthesis. Cornea. 2009;28:896-901.

39. Fadlallah A, Atallah M, Cherfan G, Awwad ST, Syed ZA, Melki SA. Gamma-irradiated corneas as carriers for the Boston type 1 keratoprosthesis: advantages and outcomes in a surgical mission setting. Cornea. 2014;33:235-9.

40. Goldman DR, Hubschman J-P, Aldave AJ, Chiang A, Huang JS, Bourges J-L, Schwartz SD. Postoperative posterior segment complications in eyes treated with the Boston type I keratoprosthesis. Retina. 2013;33:532-41.

41. Grassi CM, Crnej A, Paschalis EI, Colby K, Dohlman CH, Chodosh J. Idiopathic vitritis in the setting of Boston keratoprosthesis. Submitted to Cornea; 2014.

42. Harissi-Dagher M, Khan BF, Schaumberg DA, Dohlman $\mathrm{CH}$. Importance of nutrition to corneal grafts when used as a carrier of the Boston keratoprosthesis. Cornea. 2007;26:564-8.

43. Harissi-Dagher M, Beyer J, Dohlman $\mathrm{CH}$. The role of soft contact lenses as an adjunct to the Boston keratoprosthesis. Int Ophthalmol Clin. 2008;48:43-51.

44. Hicks CR, Crawford GJ, Tan DT, Snibson GR, Sutton GL, Downie N, Gondhowiardjo TD, Lam DS-C, Werner L, Apple D, Constable IJ. AlphaCor cases: comparative outcomes. Cornea. 2003;22:583-90.

45. Iakymenko S. Forty-five years of keratoprosthesis study and application at the Filatov Institute: a retrospective analysis of 1060 cases. Int J Ophthalmol. 2013;6:375-80.

46. Jardeleza MS, Rheaume M-A, Chodosh J, Lane AM, Dohlman $\mathrm{CH}$, Young L. Retinal detachments after Boston keratoprosthesis: incidence, predisposing factors and visual outcomes. Submitted to Retina; 2014.

47. Kanellopoulos AJ, Asimellis G. Long-term safety and efficacy of high-fluence collagen crosslinking of the vehicle cornea in Boston keratoprosthesis type 1. Cornea. 2014;33:914-8.

48. Khan BF, Harissi-Dagher M, Pavan-Langston D, Aquavella JV, Dohlman CH. The Boston keratoprosthesis in herpetic keratitis. Arch Ophthalmol. 2007;125:745-9. 
49. Lass JH, Campbell RC, Rose J, Foster CS, Dohlman CH. Medroxyprogesterone on corneal ulceration. Its effects after alkali burns on rabbits. Arch Ophthalmol. 1981;99:673-6.

50. Lekhanont K, Thaweesit P, Muntham D, Chuckpaiwong V, Vongthongsri A. Medium-term outcomes of Boston type 1 keratoprosthesis implantation in Bangkok, Thailand. Cornea. 2014;33:1312-9.

51. Linnola RJ, Happonen RP, Andersson OH, Vedel E, Yli-Urpo AU, Krause U, Laatikainen L. Titanium and bioactive glassceramic coated titanium as materials for keratoprosthesis. Exp Eye Res. 1996;63:471-8.

52. Ma JJ, Graney JM, Dohlman CH. Repeat penetrating keratoplasty versus the Boston keratoprosthesis in graft failure. Int Ophthalmol Clin. 2005;45:49-59.

53. Mannis MJ, Dohlman CH. The artificial cornea: a brief history. In: Mannis MJ, Mannis AA, editors. Corneal transplantation. A history in profiles. Oostende: JP Wayenborg; 1999. pp 321-35.

54. Melki S, Todani A, Cherfan G. An implantable intraocular pressure transducer: initial safety outcomes. JAMA Ophthalmol. 2014;132:1221-5.

55. Moroz ZI. Artificial cornea. In: Fyodorov SN, editor. Microsurgery of the eye: main aspects. Moscow: MIR; 1987. p. 27.

56. Netland PA, Terada H, Dohlman CH. Glaucoma associated with keratoprosthesis. Ophthalmology. 1998;105:751-7.

57. Nouri M, Terada H, Alfonso EC, Foster CS, Durand ML, Dohlman CH. Endophthalmitis after keratoprosthesis: incidence, bacterial causes, and risk factors. Arch Ophthalmol. 2001;119:484-9.

58. Nouri M, Durand ML, Dohlman CH. Sudden reversible vitritis after keratoprosthesis: an immune phenomenon? Cornea. 2005;24:915-9.

59. Palioura S, Kim B, Dohlman CH, Chodosh J. The Boston keratoprosthesis type I in mucous membrane pemphigoid. Cornea. 2013;32:956-61.

60. Paschalis EI, Chodosh J, Sperling RA, Salvador-Culla B, Dohlman C. A novel implantable glaucoma valve using ferrofluid. PLoS One. 2013a;8:e67404.

61. Paschalis EI, Chodosh J, Spurr-Michaud S, Cruzat A, Tauber A, Behlau I, Gipson I, Dohlman CH. In vitro and in vivo assessment of titanium surface modification for coloring the backplate of the Boston keratoprosthesis. Invest Ophthalmol Vis Sci. 2013b;54:3863-73.

62. Pascolini D, Mariotti SP. Global estimates of visual impairment: 2010. Br J Ophthalmol. 2012;96:614-8. doi:10.1136/ bjophthalmol-2011-300539.

63. Pavan-Langston D, Dohlman C. Boston keratoprosthesis treatment of Herpes zoster neurotrophic keratopathy. Ophthalmology. 2008;115:S21-3.

64. Rao GN, Blatt HL, Aquavella JV. Results of keratoprosthesis. Am J Ophthalmol. 1979;88:190-204.

65. Ray S, Khan BF, Dohlman CH, D'Amico DJ. Management of vitreoretinal complications in eyes with permanent keratoprosthesis. Arch Ophthalmol. 2002;120:559-66.

66. Rivier D, Paula JS, Kim E, Dohlman CH, Grosskreutz CL. Glaucoma and keratoprosthesis surgery: role of adjunctive cyclophotocoagulation. J Glaucoma. 2009;18:321-4.
67. Robert M-C, Biernacki K, Harissi-Dagher M. Boston keratoprosthesis type 1 surgery: use of frozen versus fresh corneal donor carriers. Cornea. 2012;31:339-45.

68. Robert M-C, Pomerleau V, Harissi-Dagher M. Complications associated with Boston keratoprosthesis type 1 and glaucoma drainage devices. $\mathrm{Br} \mathrm{J}$ Ophthalmol. 2013;97:573-7.

69. Robert MC, Arafat SN, Ciolino JB. Collagen crosslinking of the Boston keratoprosthesis donor carrier to prevent corneal melting in high-risk patients. Eye Contact Lens. 2014a;40:376-81.

70. Robert MC, Spurr-Michaud S, Frenette M, Young D, Gipson IK, Dohlman CH. Stability and in vitro toxicity of an infliximab eye drop formulation. J Pharma Comp. 2014b;18:418-26.

71. Salvador-Culla B, Behlau I, Sayegh RR, Stacy RC, Dohlman $\mathrm{CH}$, Delori F. Very low risk of light-induced retinal damage during Boston keratoprosthesis surgery: a rabbit study. Cornea. 2014a;33:184-90.

72. Salvador-Culla B, Jeong KJ, Kolovou PE, Chiang HH, Chodosh J, Langer R, Dohlman CH, Kohane DS. Titanium coating of the Boston keratoprosthesis. Submitted to Biomaterials; $2014 \mathrm{~b}$.

73. Sa-ngiampornpanit T, Thiagalingam S, Dohlman CH. Boston keratoprosthesis in epithelial downgrowth. Digit J Ophthalmol. 2009;15:1-3.

74. Sayegh RR, Dohlman CH. Wide-angle fundus imaging through the Boston keratoprosthesis. Retina. 2013;33:1188-92.

75. Sayegh RR, Ang LPK, Foster CS, Dohlman CH. The Boston keratoprosthesis in Stevens-Johnson syndrome. Am J Ophthalmol. 2008; 145:438-44.

76. Sayegh RR, Avena Diaz L, Vargas-Martin F, Webb RH, Dohlman $\mathrm{CH}$, Peli E. Optical functional properties of the Boston keratoprosthesis. Invest Ophthalmol Vis Sci. 2010;51:857-63.

77. Stone W, Herbert E. Experimental study of plastic material as replacement for the cornea; a preliminary report. Am J Ophthalmol. 1953;36:168-73.

78. Todani A, Behlau I, Fava MA, Cade F, Cherfan DG, Zakka FR, Jakobiec FA, Gao Y, Dohlman CH, Melki SA. Intraocular pressure measurement by radio wave telemetry. Invest Ophthalmol Vis Sci. 2011a;52:9573-80.

79. Todani A, Ciolino JB, Ament JD, Colby KA, Pineda R, Belin MW, Aquavella JV, Chodosh J, Dohlman CH. Titanium back plate for a PMMA keratoprosthesis: clinical outcomes. Graefes Arch Clin Exp Ophthalmol. 2011b;249:1515-8.

80. White ML, Chodosh J, Jisung J, Dohlman CH. Incidence of ocular burns (thermal, chemical) and SJS spectrum: relevance for keratoprosthesis surgery. To be submitted; 2014.

81. World Health Organization. Visual impairment and blindness. Fact Sheet No. 282. 2014;93:563-8. (Accessed on 23 Sept).

82. Yaghouti F, Nouri M, Abad JC, Power WJ, Doane MG, Dohlman $\mathrm{CH}$. Keratoprosthesis: preoperative prognostic categories. Cornea. 2001;20:19-23. 